\title{
Evaluation of Estrogenic Receptor (ER) and Aryl Hydrocarbon Receptor (AhR) Agonists in Three Gorges Reservoir, China Using SPMD-Based Virtual Organisms
}

\author{
Jingxian Wang1,2, Bernhard Henkelmann², Toine F. H. Bovee³, Gerd Pfister², Liang Zhang4, \\ Karl-Werner Schramm² \\ ${ }^{1}$ State Key Laboratory of Freshwater Ecology and Biotechnology, Institute of Hydrobiology, Chinese Academy of \\ Sciences, Wuhan, China \\ ${ }^{2}$ Helmholtz Zentrum München-German Research Center for Environmental Health (GmbH), Molecular \\ EXposomics (MEX), Munich, Germany \\ ${ }^{3}$ Department of Toxicology \& Bioassays, RIKILT, Institute of Food Safety, Wageningen, The Netherlands \\ ${ }^{4}$ School of Environmental Science and Engineering, Liaoning Technical University, Fuxin, China \\ Email: wangjx@ihb.ac.cn, schramm@wzw.tum.de
}

Received 18 January 2016; accepted 23 February 2016; published 26 February 2016

Copyright (C) 2016 by authors and Scientific Research Publishing Inc.

This work is licensed under the Creative Commons Attribution International License (CC BY).

http://creativecommons.org/licenses/by/4.0/

(c) (i) Open Access

\begin{abstract}
The evaluation of estrogenic activities and aryl hydrocarbon receptor (AhR) agonists in water from Three Gorges Reservoir (TGR) China was conducted by in vitro bioassays combined with SPMD-based virtual organisms (VO). VOs were deployed at seven sites in the Three Gorges Reservoir (TGR), China for two periods in 2009. The estrogenic activity was assessed using a rapid yeast estrogen bioassay, based on the expression of a green fluorescent reporter protein (yEGFP). The AhR activity was detected employing rat hepatoma cell line (H4IIE). The results indicate that AhR agonists distributed widely in water of TGR and almost homogenously distributed in most area of TGR. Weak antiestrogenic activities were also found homogenously distributed in water of TGR. Further studies are needed to determine the identities of these estrogenic compounds and AhR agonists and their potential adverse effects on wild biota in TGR.
\end{abstract}

\section{Keywords}

ER Activity, EROD Activity, Three Gorges Reservoir, Virtual Organism, Semipermeable Membrane Device 


\section{Introduction}

The Three Gorges Dam (TGD) constructed on the Yangtze River in China is the largest hydro-electricity project in the world and created the Three Gorges Reservoir (TGR) with an area of $1080 \mathrm{~km}^{2}$. The closing of the TGD has resulted in drastic environmental alterations especially obvious changes in dominant fish species. Over the last decades, a decline in fish catches has been reported in the Yangtze River and fish have tended to be smaller and younger. Caught fish often exhibit diseases with increased frequencies of occurrence of malformations [1]. Since the 1990s, the number of endangered fish species in the Yangtze River increased distinctly and some species disappeared [2]. There is a pressing need to address the possible ecotoxicological reasons for these fish declines. Several studies [3] [4] demonstrate that local populations of Yangtze fish may be exposed to endocrinedisrupting chemicals (EDCs) at concentrations sufficient to cause impairment of their reproductive physiology. Our recent study also detected estrogen receptor (ER) and aryl hydrocarbon receptor (AhR) activities in sediments from TGR [5]. However, limited information is available on ER and AhR activities in water of TGR.

The results from conventional chemical analysis of priority pollutants [6] and the monitoring of hydrological parameters [7] cannot explain fish decline in TGR over the last two decades [8]. The mixture of synthetic and natural organic compounds in water to which organisms are exposed can interact with each other, thus potentially modulating their toxic potential resulting in synergistic, agonistic or antagonistic effects. These effects are not considered by chemical analytical determination of exposure. In fact, chemical analysis has been used to identify and quantify only those chemicals for which analytical techniques and standards are available. Instrumental analysis does not account for interactions among the chemicals in complex mixtures and provide little information on their biological effects [9] [10]. In vitro cell bioassays offer a rapid, sensitive and relatively inexpensive solution to some of the limitations of instrumental analysis. A toxicological endpoint of high importance in the environment is ER mediated activity, which can cause hormone dependent diseases and carcinogenic effects [11]-[13]. One other relevant toxicological endpoint is AhR mediated activity, which is known to cause hepatotoxicity, teratogenesis, immunotoxicity, and tumorigenesis [14] [15].

Risk assessment for endocrine disrupters or dioxin-like compounds in surface water is difficult mainly because these compounds are usually low in concentrations, as well as the effects of many endpoints typically falling below the detection limit. In this case, necessary enrichment measures are demanded to improve the detection limit. The SPMD-based passive sampler which is also referred to be virtual organism (VO) imitates the exposure of animals in water and has been used to estimate time-integrated averages of dissolved contaminants [16] [17] and dissolved AhR agonists [18] [19]. However, few reports are available on the application of VO in determining estrogenic activities in surface water [20].

The objective of the present study was to determine ecotoxicological effect in water of TGR by using two in vitro bioassays indicative of two specific endpoints-AhR- and ER-mediated activities combined with SPMDbased VO sampling. AhR agonistic potentials were determined by the micro-EROD bioassay based on exposure of H4IIE rat hepatoma cells. Presence of ER (ant) agonists was determined by application of a yeast estrogen bioassay expressing a green fluorescent reporter protein upon exposure to estrogens.

\section{Methodology}

\subsection{SPMD-Based VO Sampler and Deployment in TGR}

The SPMD-based VO samplers were prepared in the manner described in our previous paper [17]. Briefly, the semipermeable membranes were prepared using lay-flat polyethylene tubing (from VWR Ismaning, Germany; $2.5 \mathrm{~cm}$ wide and $65 \mu \mathrm{m}$ thick). The tubing was cut into $29 \mathrm{~cm}$ pieces and $700 \mu \mathrm{L}$ of triolein (Sigma, Munich, Germany, 99\%) were pipetted into each piece of tubing before sealing the ends. The prepared VOs were stored at $-28^{\circ} \mathrm{C}$ in aluminium foil sealed heat treated $10 \mathrm{~mL}$ glass vials and kept cooled during transportation until deployment.

The sampling sites spanned the whole reservoir from the upstream Chongqing to the great dam Maoping, covering more than $600 \mathrm{~km}$ long. The sampling sites were MP (Maoping), GJB (Guojiaba), BD1 (Badong), BD2 (Badong), WZ (Wanzhou), CS (Changshou), CQ (Chongqing) (Figure 1). VOs were deployed for two periods of 14 d from April 29 to May 13 and 25 d from May 13 to June 7 in 2009 at seven sites in the TGR. The VOs were deployed in stainless steel cages and immersed into the water at about $1 \mathrm{~m}$ deep. Each cage contained 4 replicates of VOs. The samplers were mounted on boats or fastened to docks which were about 10 - $20 \mathrm{~m}$ from 


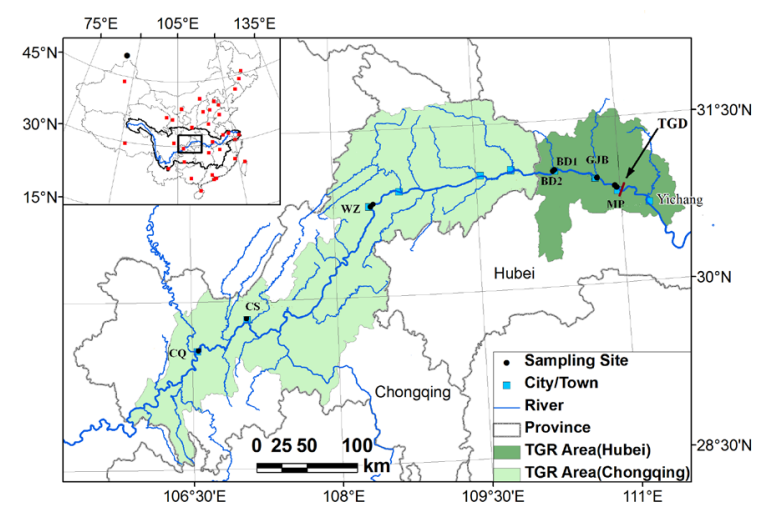

Figure 1. Scheme of sampling sites. VOs were deployed at MP (Maoping), GJB (Guojiaba), BD1 (Badong), BD2 (Badong), WZ (Wanzhou), CS (Changshou), CQ (Chongqing).

the river bank. The VOs for the determination of blanks were prepared together with the other VOs for sampling. VO blanks were transported to the sampling sites also in clean airtight jars, not deployed. After retrieval, the VOs were transported to the laboratory in the corresponding glass jars in the darkness and were kept in a freezer at $-28^{\circ} \mathrm{C}$ until processing.

\subsection{Sample Extraction and Clean up}

All organic solvents were of picograde quality and were obtained from LGC standards (Wesel, Germany). The extraction method was according to our previous study [19]. In brief, the VO was cut into small pieces and extracted in $100 \mathrm{~mL}$ cyclohexane overnight at $200 \mathrm{rpm}$ on a constant left-right shaker. The extract was passed over anhydrous sodium sulfate to remove water. The volume of the extraction solution was reduced to one drop using vacuum rotary evaporation. The triolein was removed by passing the residue through a C18 SPE cartridge for which acetonitrile was used as eluting solvent. The extract was blown to dryness with a gentle nitrogen flow and then the residue was dissolved in $200 \mu \mathrm{L}$ of a mixture of DMSO/isopropanol 4:1 (v/v) for micro-EROD bioassay and yeast bioassay.

\subsection{Micro-EROD Bioassay}

The induction of EROD activity was measured upon exposure of rat hepatoma cell line (H4IIE) to samples. The cell culture and EROD bioassay were performed according to the procedure described in our previous paper [5]. Briefly, cells were grown in Dulbecco's minimum essential medium supplemented with $10 \%$ fetal calf serum and incubated at $37^{\circ} \mathrm{C}$ in a humidified $5 \% \mathrm{CO}_{2}$ incubator. Starting the test, the cells were seeded at a density of 2 $\times 10^{4} /$ well in a 96-well plate and incubated for $24 \mathrm{~h}$ when $80 \%$ confluence was reached. The test plates with cells exposed to a serial dilution of the standard 2,3,7,8-tetrachlorodibenzo-p-dioxin (TCDD) and samples were further incubated for $24 \mathrm{~h}$ and $72 \mathrm{~h}$ and the fluorescence signals were measured at excitation $535 \mathrm{~nm}$ and emission $590 \mathrm{~nm}$. Six concentration levels of test solutions were prepared by 2-fold dilution of each VO extract (100\%, $50 \%, 25 \%, 12.5 \%, 6.25 \%, 3.13 \%)$. The standard solutions $\left(0.15,0.2,0.6,1,1.5,2.4 \mathrm{pg} \cdot \mathrm{mL}^{-1}\right.$ solvent) were prepared by serial dilution of TCDD stock solution that could yield a full dose-response curve of EROD induction and were included on each plate as positive controls and for calibration purposes. A 0.5\% DMSO/ISO 4:1 (v/v) solution was used as solvent control. All samples were tested in quadruplicate wells in the same assay. Cell viability and overall cytotoxicity of all samples were tested by use of the MTT assay as described in detail elsewhere [21]. No cytotoxic effects were observed in H4IIE cells during the exposures to the serial levels of VO extracts.

\subsection{Yeast Estrogen Bioassay}

The yeast assay used in this study is based on a cytosensor expressing the human estrogen receptor (hER $\alpha$ ) and yeast enhanced green fluorescent protein (yEGFP) in response to estrogens. The bioassay was performed according to the procedure described in our previous paper [5]. Briefly, an agar plate containing the selective 
$\mathrm{MM} / \mathrm{L}$ medium was inoculated with the yeast $\mathrm{ER} \alpha$ cytosensor from a frozen $-80^{\circ} \mathrm{C}$ stock $(20 \%$ glycerol v/v). The plate was incubated at $30^{\circ} \mathrm{C}$ for $24-48 \mathrm{~h}$ and then stored at $4^{\circ} \mathrm{C}$. The day before running the assay, a single colony of the yeast cytosensor was inoculated in $25 \mathrm{~mL}$ selective MM/L medium. This culture was grown overnight at $30^{\circ} \mathrm{C}$ with vigorous orbital shaking at $180 \mathrm{rpm}$. At the late log phase, the culture of the yeast ER $\alpha$ cytosensor was diluted in the selective MM/L medium to an OD value at $592 \mathrm{~nm}$ in the range of $0.07 \pm 0.005$. For exposure, aliquots of $200 \mu \mathrm{L}$ of this diluted yeast culture were pipetted into each well of a 96-well plate which already contained $1 \mu \mathrm{L}$ of a stock solution of sample extracts. A $17 \beta$-estradiol (E2) dose-response curve was included in each exposure experiment and the standard curve ranged from $1.2 \times 10^{-10}$ to $2 \times 10^{-9} \mathrm{M}$ E2. Two to seven concentration levels of test solutions were prepared by 2-fold dilution of each VO extract. Solvent blank DMSO/isopropanol 4:1 (v/v) and a control sample containing only E2 were included in each experiment and each sample concentration was assayed in quadruplicate wells in the same assay. The 96-well plates were incubated for $18 \mathrm{~h}$ at $30^{\circ} \mathrm{C}$ and orbital shaking with $180 \mathrm{rpm}$. Fluorescence was measured at excitation of $485 \mathrm{~nm}$ and emission of $535 \mathrm{~nm}$ in a luminescence/fluorescence multi-well plate-reader that is also able to measure optical densities (OD) (LumiCount, SPECTRA Fluor). The fluorescence signals were corrected for the signals obtained with the MM/L medium containing solvent only at the measurement time. The densities of the yeast culture were also determined by measuring the OD at $592 \mathrm{~nm}$. This was done to check whether a sample extract was toxic for the yeast cells.

To test the antagonistic properties of the extracts, the 1- $\mu \mathrm{L}$ amounts of the extract stock solutions were coexposed with $1-\mu \mathrm{L}$ of E2 solution giving about a half-maximal response. RU5866 (ToCRIS, USA) which is a strong pure synthetic antagonist was used as reference standard in the study. Solvent blank and control samples containing only E2 or E2 plus RU were included in each experiment.

\subsection{Data Analysis}

Each VO sample was measured at least three times and each sample concentration was tested in quadruplicate wells. The results of the standards were fitted and plotted by SigmaPlot (V.8.02, four parameter logistic function). The levels of AhR agonists in samples were obtained by comparing EROD activities to the TCDD concentration-response curve created using the standard solution on the same plate and expressed as TCDD equivalents (TEQ) in pg TCDD g ${ }^{-1}$ lipid (triolein). The limit of detection (LOD) was $2 \mathrm{pg}^{\mathrm{TCDD} \mathrm{g}} \mathrm{g}^{-1}$ lipid. A result is valid when the EROD activity falls in the linear part of the TCDD standard curve.

Similarly, the E2 equivalence (E2EQ) of samples was generated based on the E2 dose-response curve. The EC50 values of E2 dose-response curve were $1 \mathrm{nM}$ which was in line with those reported previously [22] [23]. The LOD was 0.2 ng E2EQ g ${ }^{-1}$ lipid.

ANOVA and t test were used to analyze difference among samples. Data were analyzed using the students t-test and the results expressed as mean \pm SD of three independent replicates.

\section{Results and Discussion}

\subsection{EROD Activity of Samples and AhR Agonists Distribution in TGR}

In this study, sample extracts were tested in the EROD assay without acid silica gel clean up, which destroys all but persistent compounds such as PCDDs/Fs. However, most organic chemicals could be metabolized by cultured cells after $72 \mathrm{~h}$ incubation [24] [25], the EROD activity after $72 \mathrm{~h}$ incubation is mainly caused by more persistent AhR agonists and that after $24 \mathrm{~h}$ incubation is defined as the total potency of the mixture of AhR agonists. As shown from Figure 2, all extracts of VO samples induced obvious responses in the H4IIE bioassay system. The EROD induction caused by sample extracts after $24 \mathrm{~h}$ of incubation (TEQ24h, total AhR agonists) ranged from 250 to 572 pg TCDD EQ g ${ }^{-1}$ lipid and after $72 \mathrm{~h}$ of incubation (TEQ72h, more persistent AhR agonists) ranged from 27 to 177 pg TCDD EQ g ${ }^{-1}$ lipid. The values of TEQ72h accounted for $9 \%$ to $31 \%$ of TEQ24h, indicating 69\% - 91\% chemicals in the extracts of VOs were less persistent and can be decomposed after longer exposure. The highest TEQ occurred in upstream of CQ and CS areas. There was no significant difference in TEQ values of VOs from the other five sampling sites.

The sediment load in the Yangtze River is $500 \mathrm{Mt}(1 \mathrm{Mt}=1,000,000 \mathrm{t})$ year $^{-1}$ [26]. After the close of the dam, the water becomes stagnant from CS to the dam for most of the year and most of the suspended sediments settle down in TGR through a natural setting process. Nearly half of trapped suspended solids in TGR settled in CS 


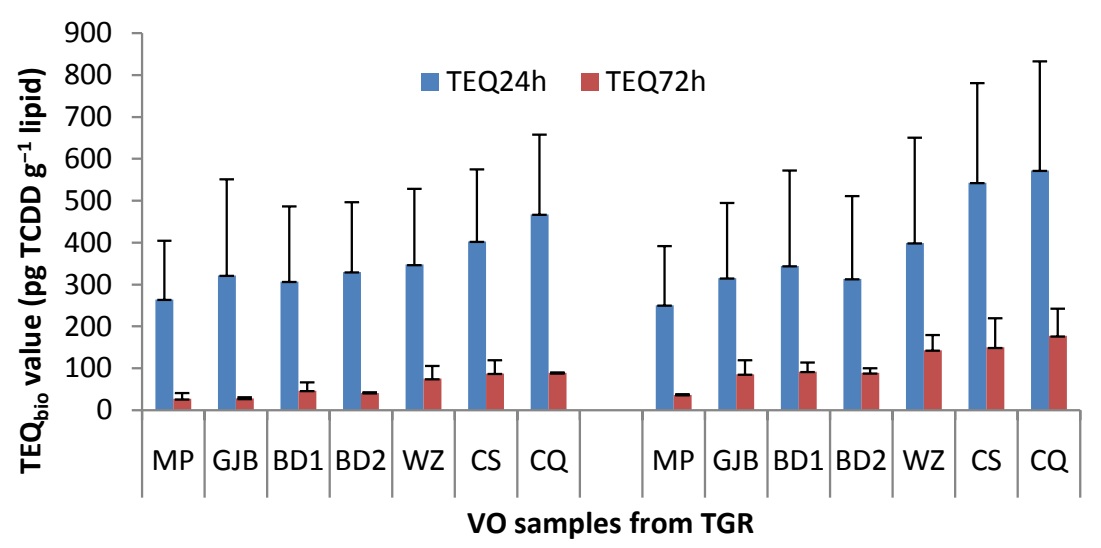

Figure 2. EROD results of VO extracts after 24 and $72 \mathrm{~h}$ incubation in H4IIE bioassay system (pg TCDD EQ g ${ }^{-1}$ lipid.)

and WZ [7], the most industrialized and urbanized areas in the TGR. Relatively small amount of suspended solids settle in less urbanized areas where close to the dam. The urbanized and industrialized areas CS and CQ may be a major source of AhR agonists for the downstream area. Some of AhR agonists may settle down with the suspended sediments which resulted in the decrease of AhR agonists in downstream area.

Our previous study [5] indicates that EROD activities in sediments from MP to WZ were 200 - 311 pg TCDD $\mathrm{EQ} \mathrm{g}^{-1}$ dry weight (dw) after $24 \mathrm{~h}$ incubation and 45 - $76 \mathrm{pg}^{\mathrm{T}} \mathrm{TDD}$ EQ g ${ }^{-1} \mathrm{dw}$ after $72 \mathrm{~h}$ incubation. The levels of AhR agonists in sediments from MP to WZ were close to those in VOs from the same area. There was no significant difference in EROD activities in the sediments from MP to WZ which is also similar to that in VOs from the same area in the present study. These indicated that AhR agonists not only distributed homogeneously in sediment but also in water in TGR from Wanzhou to the great dam. In the vast water from MP to WZ, the AhR agonists appeared to be in a dynamic equilibrium.

More persistent AhR agonists accounted for $18 \%$ to $37 \%$ of the total AhR agonists in sediments which is slightly higher than the ratio in water in the present study, indicating a little more of persistent AhR agonists settled in sediment. The majority of high affinity AhR ligands include halogenated aromatic hydrocarbons (organochlorine pesticides (OCPs), polychlorinated biphenyls (PCBs), polychlorinated dibenzo-p-dioxins (PCDD/Fs), etc.) and polycyclic aromatic hydrocarbons (PAHs). However, our previous study [5] indicates that the compounds of PAHs, PCBs, and TCDD/Fs only accounted for less than $10 \%$ of the TEQ values observed in cultured cell bioassay. Unidentified compounds in TGR have contributed to the greatest proportion of the observed TCDD EQs. Additional studies needed to determine the identities of the other AhR agonists and the ecological effect of the homogenous distribution of AhR agonists in most area of TGR.

\subsection{Estrogenic Activity of Samples}

No estrogenic activity was found in all of the VO samples and VO blanks (data not shown). In order to clarify if antagonistic effects in these VO extracts may have masked an estrogenic effect, sample extracts were coexposed with $1 \mathrm{nM}$ E2 in the estrogen bioassay and checked for antagonism. RU58668 is a synthetic compound with antiestrogenic activity in breast cells which was proven to be useful to treat patients with breast cancer. The antiestrogenic property of the compound was also tested by coadministration of $1 \mathrm{nM}$ E2. The pure antiestrogen did not show any agonistic activity (data not shown), but an inhibition of the response of more than 50\% caused by E2 that gave about a half-maximal response $(1 \mathrm{nM})$ was observed at $1 \mathrm{mM}$ (Figure 3). All of VO extracts showed weak antiestrogenic activity at their highest concentration which inhibited 37\% - 47\% of 1 nM E2 activity. Second highest concentration of VO extracts of BD WZ CS CQ inhibited 20\% - 22\% of 1 nM E2 activity and the third one did not show any antiestrogenic activities.

Our previous study detected weak estrogenic activities in sediments from WZ to GJB areas [5]. Some sediment from the upstream areas WZ demonstrated additive effects, while sediments from downstream area BD and GJB showed potential synergistic estrogenic activities, and sediments from MP showed anti-estrogenic activity. The complex ED profile in sediments in TGR was quite different from that in water where showed homogenously antiestrogenic effect. The authors attributed the complex profile of ED effects in sediments to a 


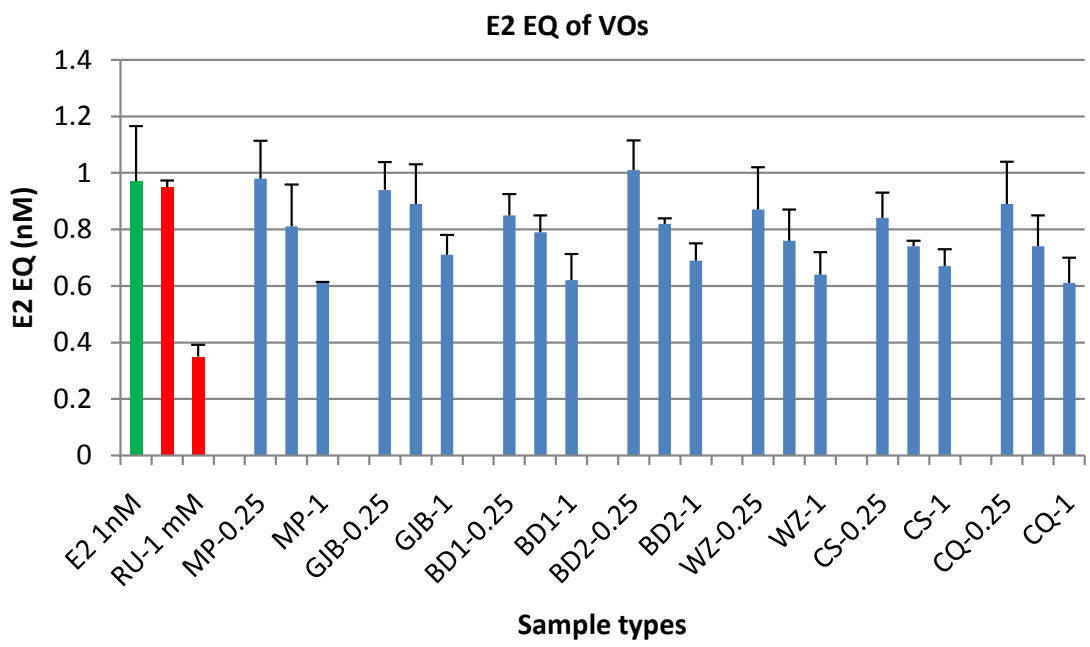

Figure 3. Estrogenic activities of VO extracts of $25 \mathrm{~d}$ exposure and RU in co-administration of $1 \mathrm{nM}$ E2 yeast bioassay system.

sedimentation effect in the reservoir. Since nearly half of trapped suspended solids in TGR settled in the most industrialized and urbanized areas CS and WZ in the TGR [7], the composition of compounds settled with suspended sediment is rather complex. Relatively small amount of suspended solids settle in less urbanized areas where close to the dam. Therefore, we speculated that the estrogenic compounds easily absorbed on particles and gradually settled into sediment during the long settling process from WZ to MP, while antiestrogenic compounds were more water soluble and could move forward with water flow. Most of the estrogenic compounds settled before the water arrived at the dam area. When the water was stopped by the dam, the water flow was almost zero and some of the antiestrogenic compounds might start to settle down with fine particles into sediment. This may explain why the estrogenic effect in sediments from TGR converted into antiestrogenic activity in the area close to the dam [5].

\section{Conclusion}

The virtual organism sampling combined with in vitro bioassays provides an effective tool for ecological risk assessment for environmentally relevant water borne pollutants in surface water. The results indicate that AhR agonists distributed widely in water of TGR and almost homogenously distributed in most area of TGR. Weak antiestrogenic activities were also found homogenously distributed in water of TGR. Many antiestrogenic compounds may be more water soluble and could move forward with water flow, while estrogenic compounds may easily absorbed on suspended particles and settle down in sediment through natural setting process. The finding of antiestrogenic and EROD activities in TGR provides possible weight-of-evidence of potential ecotoxicological causes for the declines in fish populations which have been observed during the past decades in TGR. Further studies are needed to determine the identities of the estrogenic compounds and the unidentified AhR agonists and their potential adverse effects on wild biota in TGR.

\section{Acknowledgements}

This project was funded by the German Ministry of Education and Research (BMBF 02WT1132). The modified yeast strain was a gift from Toine Bovee (RIKILT, Institute of Food Safety, Wageningen University and Research Center, The Netherlands).

\section{References}

[1] Peng, G. (2006) Present State and Protection Countermeasure for Fishery Resources in the Yangtze River in Jiangsu Section. Fishery Economic Research, 23, 18-21.

[2] Huang, L. (2006) Impacts of Hydraulic Works on Fish Biodiversity in the Yangtze River Valley and Countermeasures. Journal of Lake Sciences, 18, 553-556. http://dx.doi.org/10.18307/2006.0520 
[3] Lu, G.H., Song, W.T., Wang, C. and Yan, Z.H. (2010) Assessment of in Vivo Estrogenic Response and the Identification of Environmental Estrogens in the Ynagtze River (Nanjing Section). Chemosphere, 80, 982-990. http://dx.doi.org/10.1016/j.chemosphere.2010.05.038

[4] Shi, W., Wang, X., Hu, G., Hao, Y., Zhang, X., Liu, H., Wei, S., Wang, X. and Yu, H. (2011) Bioanalytical and Instrumental Analysis of Thyroid Hormone Disrupting Compounds in Water Sources along the Yangtze River. Environmental Pollution, 159, 441-448. http://dx.doi.org/10.1016/j.envpol.2010.10.023

[5] Wang, J., Bovee, T.F.H., Bi, Y., Bernhöft, S. and Schramm, K.-W. (2014) Aryl Hydrocarbon Receptor (AhR) Inducers and Estrogen Receptor (ER) Activities in Surface Sediments of Three Gorges Reservoir, China Evaluated with in Vitro Cell Bioassays. Environmental Science and Pollution Research, 21, 3145-3155. http://dx.doi.org/10.1007/s11356-013-2260-2

[6] Wang, J., Bi, Y., Pfister, G., Henkelmann, B., Zhu, K. and Schramm, K.-W. (2009) Determination of PAH, PCB, and OCP in Water from the Three Gorges Reservoir Accumulated by Semipermeable Membrane Devices (SPMD). Chemosphere, 75, 1119-1127. http://dx.doi.org/10.1016/j.chemosphere.2009.01.016

[7] Yin, S.-Y., Lou, B.-F., Liu, H., Lan, J., Yuan, L., Zhang, Q. and Zhang, X.-P. (2011) Analysis of Water Quality of the Yangtze River within the Three Gorges Reservoir Area during Construction Period. Resources and Environment in the Yangtze Basin, 20, 305-310.

[8] Xie, S.Q., Li, Z.J., Liu, J.S., Xie, S.Q., Wang, H.Z. and Murphy, B.R. (2007) Fisheries of the Yangtze River Show Immediate Impacts of the Three Gorges Dam. Fisheries, 32, 343-344.

[9] Brack, W. (2003) Effect-Directed Analysis: A Promising Tool for the Identification of Organic Toxicants in Complex Mixtures? Analytical and Bioanalytical Chemistry, 377, 397-407. http://dx.doi.org/10.1007/s00216-003-2139-Z

[10] Rijk, J.C.W., Bovee, T.F.H., Wang, S., Van Poucke, C., Van Peteghem, C. and Nielen, M.W.F. (2009) Detection of Anabolic Steroids in Dietary Supplements: The Added Value of an Androgen Yeast Bioassay in Parallel with a Chromatography-Tandem Mass Spectrometry Screening Method. Analytica Chimica Acta, 637, 305-314. http://dx.doi.org/10.1016/j.aca.2008.09.014

[11] Andersen, A.G., Jensen, T.K., Carlsen, E., Jorgensen, N., Andersson, A.M., Krarup, T., et al. (2000) High Frequency of Sub-Optimal Semen Quality in an Unselected Population of Young Men. Human Reproduction, 15, 366-372. http://dx.doi.org/10.1093/humrep/15.2.366

[12] Rodgers-Gray, T.P., Jobling, S., Kelly, C., Morris, S., Brighty, G., Waldock, M.J., et al. (2001) Exposure of Juvenile Roach (Rutilus rutilus) to Treated Sewage Effluent Induces Dose-Dependent and Persistent Disruption in Gonadal Duct Development. Environmental Science and Technology, 35, 462-470. http://dx.doi.org/10.1021/es001225c

[13] Toppari, J., Larsen, J.C., Christiansen, P., Giwercman, A., Grandjean, P., Guillette, L.J., Jegou, J., Bernard, J.T.K., Jouannet, P., Keiding, N., Leffers, H., McLachlan, J.A., Meyer, O., Muller, J., Rajpert-De, M.E., Scheike, T., Sharpe, R., Sumper, J. and Skakkebaek, N.E. (1996) Male Reproductive Health and Environmental Xenoestrogens. Environmental Health Perspectives, 104, 741-803. http://dx.doi.org/10.1289/ehp.96104s4741

[14] DeVito, M. and Birnbaum, L.S. (1994) Toxicology of the Dioxins and Related Chemicals. In: Schecter, A., Ed., Dioxins and Health, Plenum, New York, 139-162. http://dx.doi.org/10.1007/978-1-4899-1462-0_5

[15] Hankinson, O. (1995) The Aryl Hydrocarbon Receptor Complex. Annual Review of Pharmacology and Toxicology, 35, 307-340. http://dx.doi.org/10.1146/annurev.pa.35.040195.001515

[16] Huckins, J.N., Petty, J.D. and Booij, K. (2006) Monitors of Organic Chemicals in the Environment: Semipermeable Membrane Devices. Springer, New York.

[17] Wang, J., Henkelmann, B., Bi, Y., Zhu, K., Pfister, G., Hu, W., Temoka, C., Westrich, B. and Schamm, K.-W. (2013) Temporal Variation and Spatial Distribution of PAH in Water of Three Gorges Reservoir during the Complete Impoundment Period. Environmental Science and Pollution Research, 20, 7071-7079. http://dx.doi.org/10.1007/s11356-012-1427-6

[18] Rastall, A.C., Neziri, A., Vukovic, Z., Jung, C., Mijovic, S., Hollert, H., Nikcevic, S. and Erdinger, L. (2004) The Identification of Readily Bioavailable Pollutions in Lake Shkodra/Skada Using Semipermeable Membrane Devices (SPMDs), Bioassays and Chemical Analysis. Environmental Science and Pollution Research, 11, 240-253. http://dx.doi.org/10.1007/BF02979632

[19] Wang, J., Song, G., Li, A., Henkelmann, B., Pfister, G., Tong, A.Z. and Schramm, K.-W. (2014) Combined Chemical and Toxicological Long-Term Monitoring for AhR Agonists with SPMD-Based Virtual Organisms in Drinking Water Danjiangkou Reservoir, China. Chemosphere, 108, 306-313. http://dx.doi.org/10.1016/j.chemosphere.2014.01.056

[20] Rastall, A.C., Getting, D., Goddard, J., Roberts, D.R. and Erdinger, L. (2006) A Biomimetic Approach to the Detection and Identification of Estrogen Receptor Agonists in Surface Waters Using Semipermeable Membrane Devices (SPMDs) and Bioassay-Directed Chemical Analysis. Environmental Science and Pollution Research, 13, 256-267. http://dx.doi.org/10.1065/espr2005.12.290 
[21] Yoo, H., Khim, J.S. and Giesy, J.P. (2006) Receptor-Mediated in Vitro Bioassay for Characterization of AhR-Active Compounds and Activities in Sediment from Korea. Chemosphere, 62, 1261-1271. http://dx.doi.org/10.1016/j.chemosphere.2005.07.007

[22] Bovee, T.F.H., Heskamp, H.H., Hamers, A.R.M., Hoogenboom, L.A.P. and Nielen, M.W.F. (2005) Validation of a Rapid Yeast Estrogen Bioassay, Based on the Expression of Green Fluorescent Protein, for the Screening of Estrogenic Activity in Calf Urine. Analytica Chimica Acta, 529, 57-64. http://dx.doi.org/10.1016/j.aca.2004.07.051

[23] Simons, R., Vincken, J.-P., Mol, L.A.M., The, S.A.M., Bovee, T.F.H., Luijendijk, T.J.C., Verbruggen, M.A. and Gruppen, H. (2011) Agonistic and Antagonistic Estrogens in Licorice Root (Glycyrrhiza glabra). Analytical and Bioanalytical Chemistry, 401, 305-313. http://dx.doi.org/10.1007/s00216-011-5061-9

[24] Jones, J.M., Anderson, J.W. and Tukey, R.H. (2000) Using the Metabolism of PAHs in a Human Cell Line to Characterize Environmental Samples. Environmental Toxicology and Pharmacology, 8, 119-126. http://dx.doi.org/10.1016/S1382-6689(00)00033-8

[25] Kinani, S., Bouchonnet, S., Creusot, N., Bourcier, S., Balaguer, P., Porcher, J.M., et al. (2010) Bioanalytical Characterization of Multiple Endocrine- and Dioxin-Like Activities in Sediments from Reference and Impacted Small Rivers. Environmental Pollution, 158, 74-83. http://dx.doi.org/10.1016/j.envpol.2009.07.041

[26] Zhang, J. (1995) Geochemistry of Trace Metals from Chinese River/Estuary Systems: An Overview. Estuarine, Coastal and Shelf Science, 41, 631-658. http://dx.doi.org/10.1006/ecss.1995.0082 